\title{
Haliotrema banana sp. n. (Monogenea: Ancyrocephalidae) from Bodianus perditio (Perciformes: Labridae) off New Caledonia
}

\author{
L.H.S. Lim ${ }^{1}$ and Jean-Lou Justine ${ }^{2}$
}

\author{
${ }^{1}$ Institute of Biological Sciences, University of Malaya, Kuala Lumpur, 50603, Malaysia; \\ ${ }^{2}$ Équipe Biogéographie Marine Tropicale, Unité Systématique, Adaptation, Évolution (CNRS, UPMC, MNHN, IRD), Institut de \\ Recherche pour le Développement, BP A5, 98848 Nouméa Cedex, Nouvelle-Calédonie
}

Key words: Monogenea, Ancyrocephalidae, Haliotrema banana, Bodianus perditio, Labridae, New Caledonia

\begin{abstract}
Sixteen labrid species, including four Bodianus spp., were examined in New Caledonia (South Pacific) and monogeneans were found only on Bodianus perditio (Quoy et Gaimard). This species, Haliotrema banana sp. n., is the second Haliotrema species to be described from the labrids, the first being Haliotrema bodiani Yamaguti, 1968 from Bodianus albotaeniatus (Valenciennes), previously designated as B. bilunulatus (Lacépède). The new species is similar to H. bodiani in soft reproductive parts but differs from it in the morphologies of the hard haptoral parts, mainly in the shape of the dorsal bar (bar-shaped vs Vshaped in H. bodiani) and ventral bar. It is similar to Haliotrema spirale Yamaguti, 1968 and Haliotrema minutospirale Yamaguti, 1968 in the shape of the anchors and bars but differs from them in the detailed structures of the copulatory organ and vaginal system.
\end{abstract}

The family Labridae includes fishes commonly known as wrasses and is the second largest family of fish after Gobiidae with 68 genera and 453 species (Randall 2005). In New Caledonia alone, 114 species have been recorded (Fricke and Kulbicki 2006). Although the Labridae includes many aquarium fish species, records of monogeneans from labrids are rare and thus far only two species of ancyrocephalids belonging to two genera, two species of capsalids from two genera and one species of microcotylid have been recorded. The two ancyrocephalids are Haliotrema bodiani Yamaguti, 1968 from Bodianus albotaeniatus (Valenciennes) (previously designated as B. bilunulatus) off Hawaii and Sinodiplectanotrema argyrosomus Zhang, Yang et Liu, 2001 [type host Argyrosomus aureus, now known as Pennahia anea (Bloch) (Sciaenidae)] from Halichoeres nigrescens, off the island of Hainan, China. The two capsalids are Benedenia bodiani Yamaguti, 1968 from Bodianus albotaeniatus, off Hawaii and Neobenedenia melleni (MacCallum, 1927) from Bodianus rufus (Linnaeus), while the microcotylid, Microcotyle donavini van Beneden et Hesse, 1863 was collected from Labrus bergylta Ascanius (junior synonym L. donovani Valenciennes) in the Atlantic, off Europe and on Symphodus mediterraneus Linnaeus in the Mediterranean Sea (see Yamaguti 1968, Radujkovic and Euzet 1989, Whittington and Horton 1996, Treasurer 1997, Whittington et al. 2001).

In the present investigation monogeneans belonging to Haliotrema Johnston et Tiegs, 1922 were collected from goldspot hogfish, Bodianus perditio (Quoy et Gaimard). This new species is the second species of Haliotrema to be described from a Bodianus species and the third ancyrocephalid species described from a labrid species.

\section{MATERIALS AND METHODS}

Specimens of the labrids were caught with hand lines on board R/V "Coris" in various places off the barrier reef, Nouméa, New Caledonia at a distance of about 20-30 km from the shore, in depths of 20-40 m. Live fishes were kept in a container with sea water and immediately brought back to the laboratory. Gills were extracted and examined in sea water under a dissecting microscope. Live monogeneans were individually picked up from the gills with fine needles and immediately processed. Some monogeneans were flattened on a slide under a coverslip with a light weight on top and fixed in $70 \%$ ethanol. These were later stained in carmine as given in Justine (2005). A few specimens were prepared with ammonium picrate glycerine. Some specimens were collected from formalin-fixed gills of $B$. perditio and monogeneans were fixed and cleared in ammonium picrate glycerine. Some of these ammonium picrate glycerine fixed specimens were washed several times in distilled water to remove the fixative and then stained in Gomori's triple stain. The monogeneans were drawn with a microscope equipped with a camera lucida. Drawings were scanned and redrawn on a computer with Adobe Illustrator. Some images were taken using a Leica digital camera using Leica image analysis software (QWin Plus). All measurements (see Fig. 1) were taken on flat specimens and given in micrometres as average and range (minimum and maximum) given within parentheses.

The type specimens of $H$. bodiani USNPC 975-15, from the United States National Parasite Collection (USNPC), were examined and hard parts illustrated for comparison (Fig. 2), but we were not able to observe and hence not able to illustrate the soft anatomical parts. 
Type specimens of the present species are deposited in the Muséum National d'Histoire Naturelle, Paris (MNHN), the Muzium Zoologi Universiti Malaya, Kuala Lumpur (MZUM) and the Helminthological Collection, Institute of Parasitology, Biology Centre, Academy of Sciences of the Czech Republic, České Budějovice (HCIP).

\section{RESULTS}

Although 16 species of labrids were examined only Bodianus perditio was found to harbour monogeneans. The other 15 labrid species included three species of Bodianus, namely B. axillaris (Bennett), B. busellatus Gomon, and B. loxozonus (Snyder), as well as Cheilinus chlorourus (Bloch), C. trilobatus Lacépède, C. undulatus Rüppell, Choerodon fasciatus (Günther), C. graphicus (De Vis), Coris aygula Lacépède, Epibulus insidiator (Pallas), Oxycheilinus diagrammus (Lacépède), $O$. unifasciatus (Streets), Stethojulis strigiventer (Bennett), Thalassoma lutescens Lay et Bennett) and T. nigrofasciatum Randall.

\section{Haliotrema banana sp. $\mathrm{n}$.}

Fig. 1A-H

Description. Body elongate, length 635 (463-842) width 176 (128-211), anterior region with 3 pairs of cephalic glands of dactylogyrid-type and 2 pairs of pigmented eye-spots. Mouth subterminal ventral; pharynx oval comparatively small; intestine bifurcates posterior to pharynx; caeca rejoin posterior to testis and anterior to short peduncle.

Haptor set off from body, almost rectangular; length 89 (72-120) width 124 (103-149), 14 larval type marginal hooks, similar size, length 13 (12-14); two pairs of anchors with fenestrated shafts; 2 dorsal anchors with inner length 60 (55-64); outer length 49 (42-55), long inner root $24(18-30)$, outer root $10(6-13)$; point 17 (13-20); 2 ventral anchors with well-developed roots, inner length 63 (58-68), outer length 49 (46-54), long inner root $30(26-37)$, outer root $10(8-12)$, point 17 (10-21); 2 connecting bars: straight dorsal bar, 43 (3847) wide; U-shaped ventral bar, 43 (38-49) wide.

Testis single, round, larger than ovary, postero-dorsal to and overlapping ovary; vas deferens leaves anteromedial region of testis, passes along dorsal to loop sinistral caecum to ventral side, ascends in intercaecal region to anterior part of copulatory organ, loops downwards, distends forming seminal vesicle, narrows to enter initial part of copulatory tube. Single elongate pyriform prostatic reservoir prominent, prostatic gland ducts drain into the anterior part of prostatic reservoir; prostatic duct leaves reservoir to enter initial part of copulatory tube. Copulatory organ consists of copulatory tube, length 110 (99-120) with a long base and sinuous tapering tube and thin filament (accessory piece) at distal tip of tube.

Ovary elongate, in mid-body; oviduct arises from anterior of ovary, receives thin vaginal duct from distal part (not tip) of the flask-like saccular vagina (see later) and vitelline ducts, proceeds anteriorly to form oötype, receiving ducts from surrounding Mehlis' gland, ascends medially as uterus to open postero-ventrally to copulatory organ. Dextral vaginal system with prominent large muscular elongate flask- or pear-shaped distal end traversing into midportion of body; large pore probably opening into thin-walled small seminal receptacle, thin sclerotized vaginal duct (observed not at tip of flask-shaped vagina) probably leaving seminal receptacle to oviduct. Vitelline system confluent anterior to haptor.

T y p e hos t: Bodianus perditio (Quoy et Gaimard) (Perciformes: Labridae).

$\mathrm{S}$ i t e : Between secondary gill lamellae.

T y p e 1 o c a 1 i t y: Barrier reef off Nouméa, New Caledonia.

T y p e s p e c i m e n s : Holotype, MNHN JNC 1028A1; MNHN, 18 paratypes (JNC996, JNC1003, JNC1027, JNC1028, JNC1151, JNC1199); MZUM(P), 3 paratypes (nos. 578-580); HCIP, 2 paratypes (M-434).

M a t e r i a 1 s t u d i e d : 22 specimens; 20 specimens measured.

Prevalence: $75 \%(26 / 35)$.

In t e n s i t y : Up to about 100 monogeneans per fish.

Comparative material studied: Slide USNPC 975-15, Haliotrema bodiani Yamaguti, 1968; the single slide contains the holotype, clearly marked, and 15 other specimens or fragments (all paratypes).

E t y m o lo g y: The species name is after the local name of the fish "perroquet banane". Name in apposition, indeclinable.

Remarks on the host. The goldspot hogfish $\mathrm{Bo}$ dianus perditio is the second largest labrid in New Caledonia (after the giant humphead wrasse, Cheilinus undulatus). It is locally known as "perroquet banane" (to be translated as "banana parrot fish") probably because it superficially resembles the parrot fishes (family Scaridae) by its large scales and brilliant colours, and because it is often yellow as a banana. The fish is common and often seen at the Nouméa market where it is sold with the parrot fishes.

Differential diagnosis. This new species is different from $H$. bodiani in the shape of the bars (Figs. 1,2) and the extent of the flask-shaped vaginal system (see fig. 42 in Yamaguti 1968). In H. banana, the flask-like vagina extends beyond the midbody almost to the left side of the body traversing the initial part of the elongate copulatory tube, while in $H$. bodiani the flask-like vagina is located some distance posterior to the copulatory tube and does not extend to beyond the midbody. However, it is not certain if this is due to different methods of preparation. The copulatory organ of the present species resembles that of $H$. bodiani $(88 \mu \mathrm{m})$ (Figs. 1, 2), except that in the present species the copulatory organ is larger $(110 \mu \mathrm{m})$. The anchors of $H$. banana and those of $H$. bodiani are similar but the dorsal bar of the new 

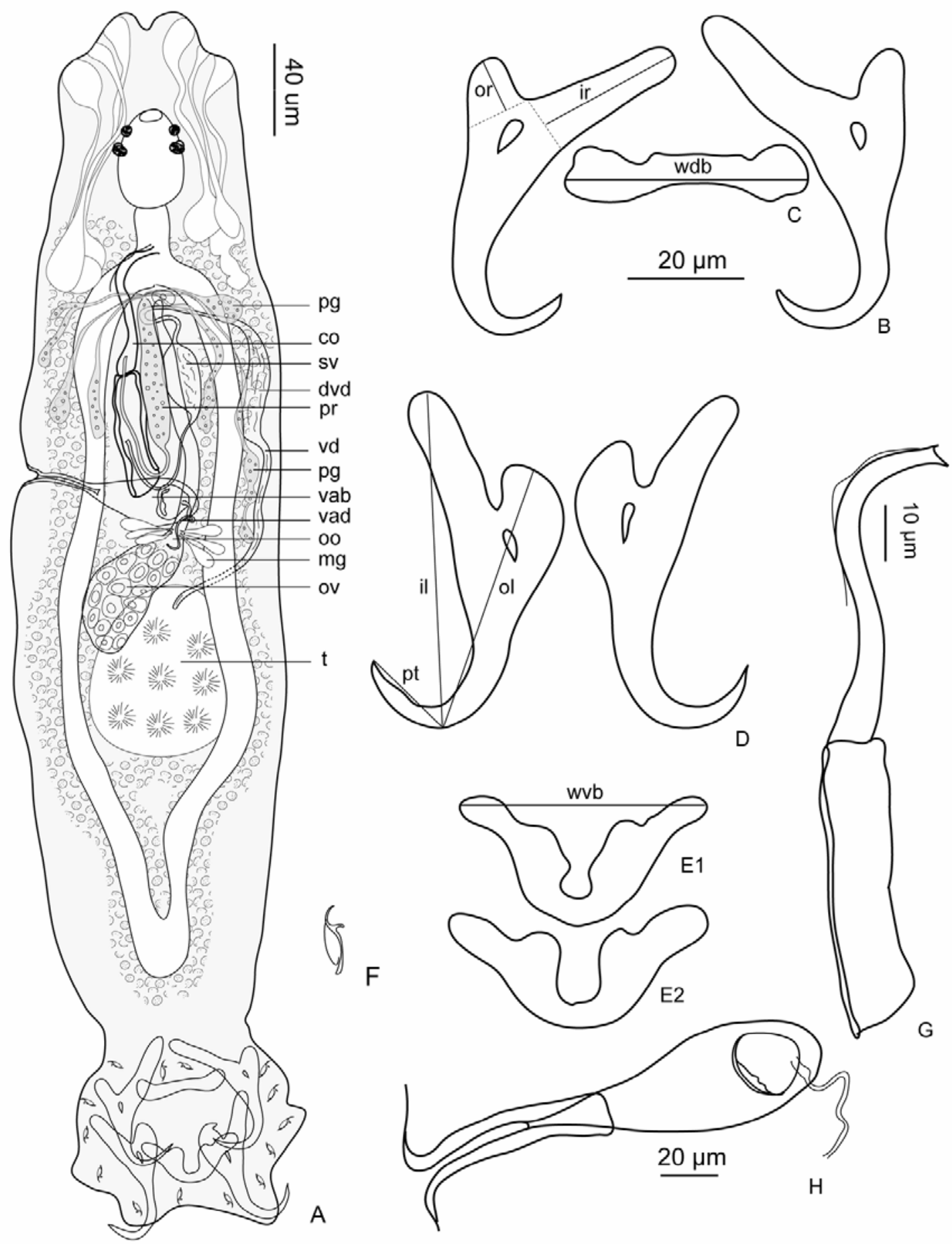

Fig. 1. Haliotrema banana sp. n. A - composite illustration, ventral view (pg - prostatic gland; co - copulatory organ; sv - seminal vesicle; dvd - distended vas deferens; pr - prostatic reservoir; vd - vas deferens; vab - vaginal bulb; vad - vaginal duct; oo - oötype; mg - Mehlis' gland; ov - ovary; t - testis); B - dorsal anchor (ir - inner root; or - outer root); C - dorsal bar (wdb - width of dorsal bar); D - ventral anchor (il - inner root length; ol - outer root length; pt - point); E1, E2 - ventral bar (wvb - width of ventral bar); $\mathbf{F}$ - marginal hook; $\mathbf{G}$ - copulatory tube; $\mathbf{H}$ - vagina. 


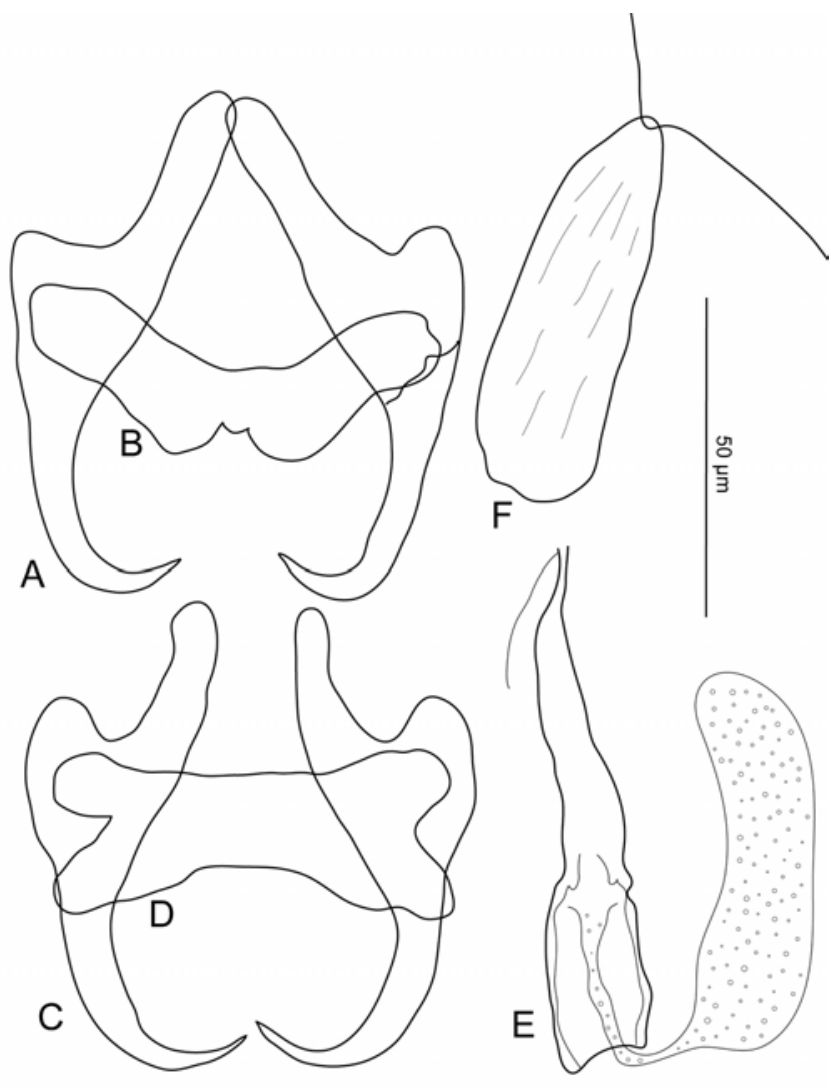

Fig. 2. Haliotrema bodiani Yamaguti, 1968, hard parts of holotype. A - dorsal anchor; B - dorsal bar; C - ventral anchor; $\mathbf{D}$ - ventral bar; $\mathbf{E}$ - copulatory tube; $\mathbf{F}$ - vagina.

species is bar-shaped while that of $H$. bodiani is a broad $\mathrm{V}$-shaped bar. The ventral bar is also different in the two species (Figs. 1, 2).

Other Haliotrema species with similar large flasklike vaginae include $H$. cancescens Yamaguti, 1968, $H$. ctenochaeti Yamaguti, 1968, H. curvicirrus Yamaguti, 1968, H. flexicirrus Yamaguti, 1968, H. macracantha Yamaguti, 1968, H. palmatum Yamaguti, 1968, H. serpenticirrus Yamaguti, 1968, H. spirale Yamaguti, 1968, while H. brotulae Yamaguti, 1968 (annulocirrus group), $H$. chelicirrus Yamaguti, 1968, H. rectangulare Yamaguti, 1968, H. priacanthi Yamaguti, 1968 and H. sigmodocirrus Yamaguti, 1968 have smaller vaginal 'flasks' and longer vaginal ducts (Klassen 1994). Based on the combination of vaginal 'flask', U-shaped ventral bar and copulatory organ, this new species is similar to $H$. spirale from Brotula multibarbata Temminck et Schlegel and $H$. minutospirale Yamaguti, 1968 from Parupeneus cyclostomus Lacépède (junior synonym $P$. chryserydros), P. pleurostigma Bennett and P. multifasciatus Quoy et Gaimard. However, in $H$. spirale the filament-like accessory piece is more prominent and longer while in $H$. banana the filamentous accessory piece is not obvious. Haliotrema minutospirale is different from this new species in the shape of the vagina as well as in the copulatory organ.

\section{DISCUSSION}

This new species of Haliotrema has a large flaskshaped vagina, a small medial ovary, a large round dorsal testis with the vas deferens looping the left intestinal caecum to the ventral side, a simple copulatory organ, a large prominent prostatic reservoir, four anchors, two bars and 14 marginal hooks. Klassen (1994) in his analysis of Haliotrema species from boxfishes proposed a bodiani group which included $H$. bodiani, $H$. balisticus (MacCallum, 1915), H. priacanthi, H. pacificus (Mizelle et Kritsky, 1969), H. cornutus (Mizelle et Kritsky, 1969), H. ornatum Yamaguti, 1968 and H. teuthis (MacCallum, 1915). The present new species is different from the Haliotrema species within the bodiani group. A prominent flask-shaped vagina as observed in the present new Haliotrema is found in other Haliotrema species not within the bodiani group (Klassen 1994); for instance $H$. spirale has a vagina of similar shape, copulatory organ and anchors but belongs to the spirale group.

This is the third ancyrocephalid species for the Labridae and the second ancyrocephalid species to be described from a Bodianus species. The first species, $H$. bodiani was described by Yamaguti (1968) from Bodianus bilunulatus (Lacépède) off Hawaii. According to the latest revision of Bodianus by Gomon (2006), B. bilunulatus is restricted to the Indian Ocean and Central Pacific, and the host of $H$. bodiani should now be designated as Bodianus albotaeniatus (Valenciennes) (previously considered a subspecies of $B$. bilunulatus).

Gomon (2006) recognized 43 species and 10 subgenera in Bodianus; interestingly, B. albotaeniatus and $B$. perditio, the two species in which monogeneans have been found, are both members of the subgenus Diastodon Bowdich, 1825. No ancyrocephalid has been recorded from the other nine subgenera. However, not all members of Diastodon harbour ancyrocephalid monogeneans, shown by their absence in two other species of the subgenus, B. (D.) busellatus and B. (D.) loxozonus, which we have examined in New Caledonia. As already noted the capsalids recorded from Bodianus spp. are Benedenia bodiani from $B$. (D.) albotaeniatus and Neobenedenia melleni from $B$. rufus, a member of the subgenus Bodianus. It should be noted that $N$. melleni is a species with wide host specificity and common under culture situations (Whittington and Horton 1996). No capsalid has been found on any of the Bodianus spp. nor on any of the labrids examined thus far in New Caledonia. However, the report (Zhang et al. 2001) of Sinodiplectanotrema argyrosomus, previously described from the sciaenid, Pennahia anea, on the labrid Halichoeres nigrescens, should be re-evaluated.

The paucity of monogeneans on Labridae, despite being a species-rich family (see Introduction), is further corroborated by the fact that of the 16 labrid species examined in New Caledonia, only one species, B. perditio was found to harbour monogeneans. However, this 
paucity of monogeneans is not paralleled by other parasitic groups. Besides $H$. banana, the gills of $B$. perditio are inhabited by four species of copepods, Hatschekia sp. (Hatschekiidae), Dissonus sp. (Dissonidae), Lepeophtheirus sp. (Caligidae) and Lernanthropus sp. (Lernanthropidae) and one larval gnathiid isopod (Justine, personal observation). Eggs of Huffmanela ossicola Justine, 2004, a trichosomoidid nematode described from Bodianus loxozonus (see Justine 2004), were found within the arch gill bones and other bones of $B$. perditio (new host record). The digestive tract harbours the lepocreadiid digenean Intusatrium robustum Durio et Manter, 1968 (Durio and Manter 1968, Bray and Justine 2006) and an unidentified cucullanid nematode. In total the fish harbours nine parasite species, including seven in the gills.

It is interesting to note that the Gobiidae, the largest marine fish family, is also relatively poor in monogenean fauna and has a single Haliotrema species (Sasal et al. 1998) reported thus far.
Acknowledgements. Identification of all Bodianus specimens mentioned in this paper was kindly confirmed (from photographs) by Martin Gomon (Museum Victoria, Melbourne, Australia), who also provided comments and literature; identification of most other labrids was kindly confirmed (from photographs) by Ronald Fricke (Staatliches Museum für Naturkunde, Stuttgart, Germany). We thank Eric Hoberg (USNPC, Beltsville, USA) for providing type specimens. G.A. Boxshall (Natural History Museum, London) kindly identified copepods. Louis Euzet (Sète, France) helped with an early study of these specimens. Julie Mounier, volunteer technician, and Charles Beaufrère, Audrey Guérin, Anaïs Guillou, Amandine Marie, Chloé Journo, Violette Justine, Eric Bureau, Maya Robert, Damien Hinsinger, Géraldine Colli, Lenaïg Hemery and Aude Sigura, all students, participated in the fishing operations and parasitological survey. Sam Tereua, Miguel Clarque and Napoléon Colombani, captains of the RV 'Coris' provided safe navigation. Angelo di Matteo (IRD) provided technical help. We would like to thank Mr. K.S. Liew for technical assistance in collecting and processing the specimens. This project was made possible by the kind assistance from the staff of the French Embassy in Kuala Lumpur and funds from the French Embassy, Kuala Lumpur.

\section{REFERENCES}

BRAY R., JUSTINE J.-L. 2006: Hypocreadium toombo n. sp. (Digenea: Lepocreadiidae) in the yellow-spotted triggerfish Pseudobalistes fuscus (Perciformes: Balistidae) and additional lepocreadiids parasitizing fishes from the waters off New Caledonia. Zootaxa 1326: 37-44.

DURIO W.O., MANTER H.W. 1968: Some digenetic trematodes of marine fishes of New Caledonia. Part II. Opecoelidae and Lepocreadiidae. J. Parasitol. 54: 747-756.

FriCKE R., KULBICKI M. 2006: Checklist of the shore fishes of New Caledonia. In: C. Payri and B. Richer de Forges (Eds.), Compendium of Marine Species from New Caledonia. Documents Scientifiques et Techniques 117. Institut de Recherche pour le Développement, Nouméa, New Caledonia, pp. 313-357.

GOMON M. 2006: A revision of the labrid fish genus Bodianus with descriptions of eight new species. Rec. Aust. Mus., Suppl. 30: 1-133.

JUSTINE J.-L. 2004: Three new species of Huffmanela Moravec, 1987 (Nematoda, Trichosomoididae) from the gills of marine fish off New Caledonia. Syst. Parasitol. 59: 29-37.

JUSTINE J.-L. 2005: Species of Pseudorhabdosynochus Yamaguti, 1958 (Monogenea, Diplectanidae) from Epinephelus fasciatus and E. merra (Perciformes, Serranidae) off New Caledonia and other parts of the Indo-Pacific Ocean, with a comparison of measurements of specimens prepared with different methods and a description of $P$. caledonicus n. sp. Syst. Parasitol. 62: $1-37$.

KLASSEN G.J. 1994: Phylogeny of Haliotrema species (Monogenea: Ancyrocephalidae) from boxfishes (Tetraodontiformes, Ostracidae): are Haliotrema from boxfishes monophyletic? J. Parasitol. 80: 596-610.
RADUJKOVIC B.M., EUZET L. 1989: Parasites des poissons marins du Montenegro: Monogènes. Acta Adriatica, Split 30: 51135.

RANDALL J.E. 2005: Reef and Shore Fishes of the South Pacific. New Caledonia to Tahiti and the Pitcairn Islands. University of Hawaii Press, Honolulu, 707 pp.

SASAl P., PAGĖS J.-R., EUZET L. 1998: Haliotrema cupensis $\mathrm{n}$. sp. (Monogenea, Ancyrocephalidae) from a marine gobiid (Teleostei, Perciformes) of the Mediterranean Coast. Syst. Parasitol. 39: 107-112.

TREASURER J.W. 1997: Parasites of wrasse (Labridae) in inshore waters of west Scotland stocked as cleaner fish of sea lice (Caligidae) on farmed Atlantic salmon J. Fish Biol. 50: 895899.

WHITTINGTON I.D., DEVENEY M.R., WYBORN S.J. 2001: A revision of Benedenia Diesing, 1858 including a redescription of B. sciaenae (van Beneden, 1856) Odhner, 1905 and recognition of Menziesia Gibson, 1976 (Monogenea). J. Nat. Hist. 35: 663-777.

WHITTINGTON I.D., HORTON M.A. 1996: A revision of Neobenedenia Yamaguti, 1963 (Monogenea: Capsalidae) including a redescription of $N$. melleni (MacCallum, 1927) Yamaguti, 1963. J. Nat. Hist. 30: 1113-1156.

YAMAGUTI S. 1968: Monogenetic Trematodes of Hawaiian Fishes. University of Hawaii Press, Honolulu, $287 \mathrm{pp}$.

ZHANG J.Y., YANG T.B., LIU L. 2001: Monogeneans of Chinese Marine Fishes. Agriculture Press, Beijing, 400 pp. (In Chinese.) 